\title{
A Rare Case of Left Sided Congenital Chylothorax in a Female Child of an IVF Pregnancy Complicated with Pregnancy Induced Hypertension - Multidisciplinary Approach
}

\author{
Shubhasis Banerjee', Rohit Kapoor² \\ 1,Department of Obstetrics and Gynaecology, Sri Aurobindo Seva Kendra (EEDF Hospital), Kolkata, \\ West Bengal, India. ${ }^{2}$ Department of Paediatrics, Institute of Child Health, Kolkata, West Bengal, India.
}

\section{INTRODUCTION}

Congenital idiopathic chylothorax, characterised by accumulation of lymphatic fluid in pleural cavity, is the commonest cause of perinatal pleural effusion. In most of the cases, the reason is unknown, but it can be associated with different genetic disorders and complex array of diseases. Most of the clinical manifestations are caused due to loss of lymphatic fluid into the pleural cavity and thus causing pressure effect. The management is chiefly conservative, though may require surgical intervention in few cases and can be very challenging. Congenital chylothorax has a very high mortality rate if associated with syndromes.

\section{PRESENTATION OF CASE}

A 25-year-old primigravida, who conceived by IVF technique and developed pregnancy induced hypertension during late trimester, had a scheduled ultrasound growth scan at $29^{+6}$ weeks of gestation which revealed isolated left sided massive pleural effusion without hydrops fetalis or any other detectable gross radiological anomaly. There was evidence of ipsilateral lung collapse and cardiac shift to the right side. Serial weekly U / S (Ultra-Sound) scan detected constant progression of left sided pleural effusion and development of polyhydramnios at $31^{+6}$ weeks of gestation. Ultrasound guided thoracocentesis done twice, at $32^{+4}$ weeks, and $33^{+5}$ weeks respectively to obtain $50 \mathrm{ml}$ of dark straw-coloured fluid on each occasion. However, there was no improvement of the condition as pleural effusion returned almost to the same extent within 48 hours of intervention. Serial increment of polyhydramnios was noted and mother developed moderate PIH (Pregnancy Induced Hypertension) at $35^{+5}$ weeks which compelled to deliver the baby by caesarean section after giving a dose of antenatal steroid prophylaxis.

A healthy female child, weighing 2560 gms, was delivered. The baby cried at birth, but had Apgar score of $4 \& 6$ respectively at the end of $1 \mathrm{~min}$ and $5 \mathrm{~min}$. No breathing sound noted on the left side of the chest and baby developed acrocyanosis. Baby was intubated inside the theatre and subsequently shifted to NICU (Neonatal Intensive Care Unit) giving invasive ventilation. Parenteral nutrition commenced with $80 \mathrm{ml} /$ $\mathrm{kg} /$ day; IV antibiotics started and routine blood investigations ordered. A chest roentgenogram image 1 was done which revealed massive left sided pleural effusion. A chest drain was placed at the $5^{\text {th }}$ ICS (Inter-Costal Space) in mid-clavicular line. Diagnostic as well as therapeutic pleural tapping was done and fluid sent for cell count and biochemistry.
Corresponding Author:

Dr. Shubhasis Banerjee,

Department of Obstetrics \&

Gynaecology, SASK (EEDF Hospital),

1H, Gariahat Road,

Kolkata - 700068, West Bengal,

India.

E-mail: banerjeecalcutta@gmail.com

DOI: $10.14260 /$ jemds/2020/770

How to Cite This Article:

Banerjee S, Kapoor R. A rare case of left sided congenital chylothorax in a female child of an IVF pregnancy complicated with pregnancy induced hypertension multidisciplinary approach. J Evolution Med Dent Sci 2020;9(46):3512-3513, DOI: $10.14260 /$ jemds/2020/770

Submission 05-08-2020,

Peer Review 01-10-2020,

Acceptance 09-10-2020,

Published 16-11-2020.

Copyright (C) 2020 Shubhasis Banerjee et al. This is an open access article distributed under Creative Commons Attribution License [Attribution 4.0 International (CC BY 4.0)] 
Reports of pleural fluid showed glucose ( $82 \mathrm{mg} \%$ ), protein (3.4 gm \%), cell count 1400 cell / cu.mm with lymphocytic predominance (93\%) which confirms the diagnosis of chylothorax. Feeding started from the evening on the day after delivery and subsequently MCT (Medium Chain Triglyceride) oil added. Breathing sound improved over few days and chest roentgenogram confirms it radiologically.

\section{PATHOLOGICAL DISCUSSION}

Idiopathic congenital chylothorax is a very rare (1 in every 10,000 live births) ${ }^{1-4}$ but commonest cause of pleural effusion in perinatal period. It results from lymphatic fluid collection in the pleural cavity secondary to leakage of lymph from thoracic duct or its tributaries. Chylothorax complicated with hydrops fetalis or other syndromes often becomes challenging in terms of management. Occurrence of congenital chylothorax is observed as male: female $(2: 1)$ ratio without any racial discrimination. Because of its anatomical, metabolic and nutritional complications, significant long-term morbidity and mortality $(20-60 \%)^{1-4}$ is noted. If chylothorax is associated with hydrops fetalis, mortality rate can further rise up to 98 $\%{ }^{1}$ Most of the clinical manifestations are due to pressure effect (pulmonary hypoplasia, congestive cardiac failure and hydrops).1,2,5

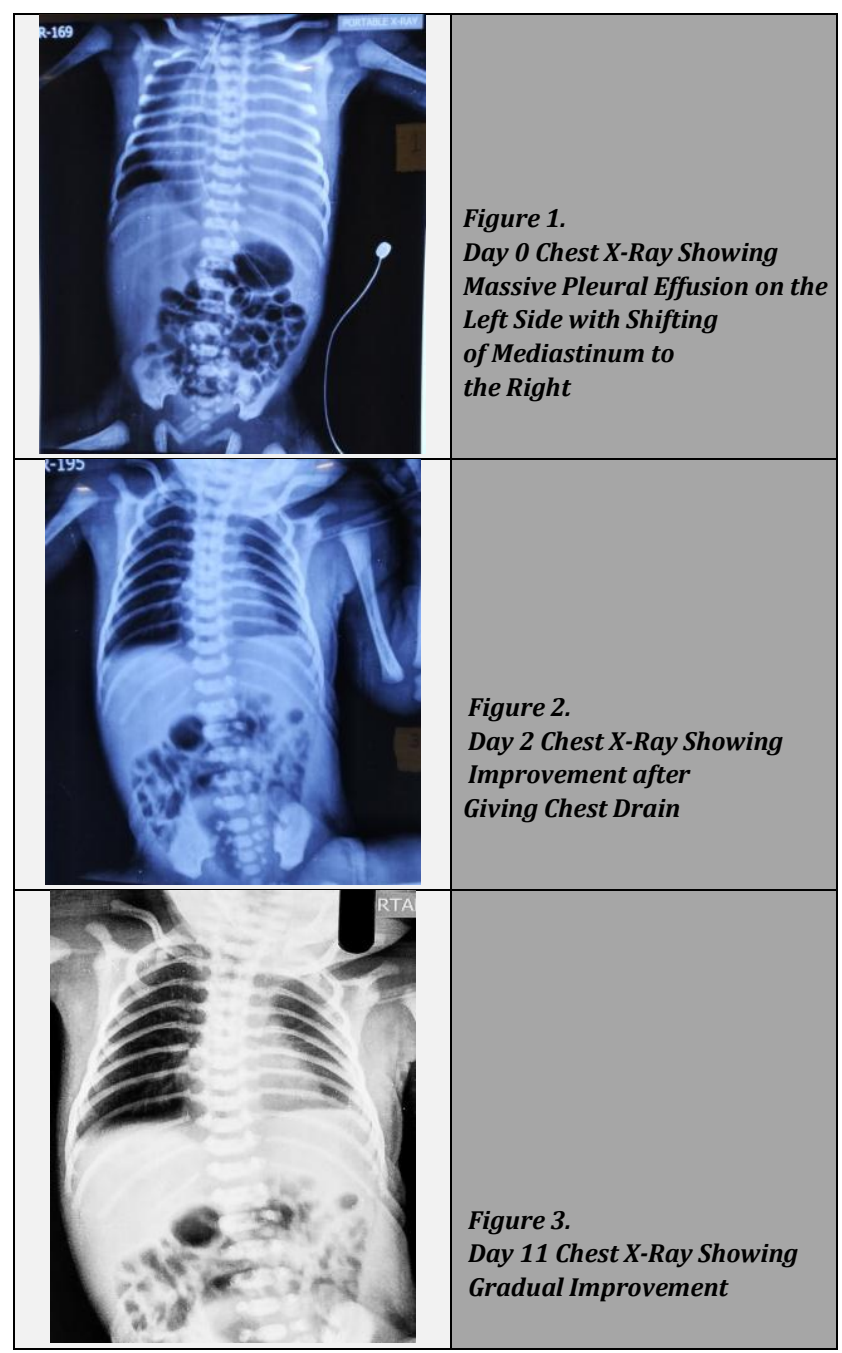

\section{DISCUSSION}

The treatment approach for chylothorax is chiefly subdivided into two categories, prenatal and postnatal. Infants, who are diagnosed before 34 weeks intrauterine age, experiences better perinatal and postnatal outcome. ${ }^{6}$ In most of the cases, the condition resolves in first few weeks ( $2-6$ weeks) with conservative management. ${ }^{7,8}$ Strategies for the treatment of chylothorax include drainage of chyle from pleural space (by thoracocentesis and continuous drainage), maintenance of nutrition, fluid and electrolytes in body, reduction in chyle volume with dietary modifications (low fat diet, MCTs or by using octreotide) and surgical methods (pleuro-peritoneal shunt or diaphragmatic fenestration). In some extreme cases, thoracic duct ligation or embolisation may be considered. In our case, the child responded well with conservative management and has been showing improvement which is established by serial chest roentgenogram image 2,3.

Financial or other competing interests: None.

Disclosure forms provided by the authors are available with the full text of this article at jemds.com.

We are thankful to Dr Madhab Chandra Das, FRCOG (Lond) and Dr Atanu Kumar Jana, MD (Paediatrics) for their valuable opinion regarding the case.

\section{REFERENCES}

[1] Al-Tawil K, Ahmed G, Al-Hathal M, et al. Congenital chylothorax. Am J Perinatol 2000;17(3):121-6.

[2] de Beer HG, Mol MJ, Janssen JP. Chylothorax. Neth J Med 2000;56(1):25-31.

[3] Dendale J, Comet P, Amram D, et al. Prenatal diagnosis of chylothorax. Arch Pediatr 1999;6(8):867-71.

[4] Dubin PJ, King IN, Gallagher PG. Congenital chylothorax. Curr Opin Pediatr 2000;12(5):505-9.

[5] Van Straaten HL, Gerards LJ, Krediet TG. Chylothorax in the neonatal period. Eur J Pediatr 1993;152(1):2-5.

[6] Lee CJ, Tsao PN, Chen CY, et al. Prenatal therapy improves the survival of premature infants with congenital chylothorax. Pediatr Neonatol 2016;57(2):127-32.

[7] Beghetti M, La Scala G, Belli D, et al. Etiology and management of pediatric chylothorax. J Pediatr 2000;136(5):653-8.

[8] Cohan RH, Saeed M, Schwab SJ, et al. Povidone-iodine sclerosis of pelvic lymphoceles: a prospective study. Urol Radiol 1988;10(4):203-6. 